\title{
Low back pain: in search of goddess Panacea
}

\section{R. Gunzburg}

Accepted: 16 September 2014/Published online: 25 September 2014 (C) Springer-Verlag Berlin Heidelberg 2014

Figuratively, Panacea is something intended to completely solve a large, multi-faceted problem.

At times, a single paper is deemed of sufficient importance to be published in more than one journal. This is the case for the focus article on research standards for chronic low back pain reprinted here. As researchers use varied inclusion criteria, definitions, baseline assessments, and outcome measures, which impede comparisons and consensus, a research task force was charged to draft standards for research on LBP. The results included recommendations for definitions, a minimum dataset, reporting outcomes, and future research. The authors believe that these recommendations will advance the field, help to resolve controversies, and facilitate future research addressing the genomic, neurologic, and other mechanistic substrates of chronic low back pain [1].

Submissions to the European Spine Journal reflect the importance low back pain has on us as individuals experiencing illness because of low back pain. It prompts clinicians and researchers worldwide to tackle the problem from all possible angles. We have papers on biomechanics and diagnostics and quite a few dealing with outcomes. Of course the notion that fusion or disc replacements are the answer to low back pain, is well-anchored. This issue includes papers from UK, Australia, USA, Switzerland, France, China, Sweden, Japan, Italy and Korea, and will lead the readers from prevention over diagnostics to conservative management, surgery and outcome analyses. However, it will take many more issues before we discover where Panacea actually roams.

Conflict of interest None.

\section{Reference}

1. Deyo RA et al (2014) Focus article: report of the NIH task force on research standards for chronic low back pain. Eur Spine J. doi:10. 1007/s00586-014-3540-3

R. Gunzburg $(\bowtie)$

Cavell Spine Centre, Edith Cavell Clinic, Edith Cavell Street 32,

1180 Brussels, Belgium

e-mail: robert@gunzburg.be 